\title{
Social media intelligence
}

Web-intelligence is not new to intelligence studies. IT plus intelligence has been the most frequent topic of the issues published the past years. Thus Vol 8, No 1 (2018) is entitled "The disciplines of management and IT have indeed merged: new empirical data", Vol 7, No 1 (2017) "Business intelligence, big data and theory" and Vol 6, No 3 (2016) "What role does technology play for intelligence studies at the start of the 21st century?". Special issues have looked at the problem of IT failures in relation to business intelligence: "How companies succeed and fail to succeed with the implementation of intelligence systems", Vol 7, No 3 (2017) and "How companies work and fail to work with business intelligence, Vol 7, No 2 (2017). During the past years companies have indeed learned from their failures. Maybe this phase was inevitable as a part of growing up. We see the same development on e-commerce sites: they mostly work well now, but didn't just a few years ago. A certain difference between countries still exists, but the industry is getting there. Closely related to failures of implementation are user perspectives on business intelligence systems, which have resulted in numerous research articles. A well-cited article by Adamala and Cidrin (2011) led to the development of several models and theories as presented, for example, in Vol 6, No 2 (2016) entitled "User perspectives on business intelligence".

The focus in JISIB is always technology. It is more a question of which aspect of technology we focus on. In this issue, it is social media or social media intelligence. The paper by Gioti and Ponis entitled "Social business intelligence: Review and research directions" is a literature review exploring the new direction of social business intelligence (SBI), where social media meets BI. The last paper is entitled "Business intelligence for social media interaction in the travel industry in Indonesia". The authors, Yulianto, Girsang and Rumagit propose a way to develop a data warehouse to analyze data from social media, such as likes, comments and sentiment, applied to the travel industry in Indonesia.

Another aspect of the journal maintains the tradition of intelligence studies in general. Intelligence studies must always be broad to be relevant and not to miss important pieces. Specialization is a necessity and a curse at the same time. Vol 6, No 1 (2016) in entitled "The width and scope of intelligence studies in business". A part of this width and critique has involved self-reflection. Thus earlier articles in JISIB often discussed methods. Case studies (by country or industry) were always a favorite. In Vol 4, No 3 (2014) JISIB continued this tradition of publishing case studies. In Vol 3, No 2 (2013), the whole issue is dedicated to one country; Brazil. Analyzing patents analysis has also been a frequent and reoccurring topic. In this issue both of these directions are represented. The third article is entitled "Investigating the competitive intelligence practices of Peruvian fresh grapes exporters," written by Bisson, Mercedes, and Tong. The authors suggest a number of changes for Peruvian grapes exporters to become more competitive based on a CI approach.

The fourth paper by Shaikh and Singhal entitled "An analysis of ip management strategies of ict companies based on patent filings" tries to identify the strategies of five US and Indian IT companies by analyzing their patents. The first paper by Nuortimo is entitled "Measuring public acceptance with opinion mining: The case of the energy industry with long-term coal R\&D investment projects" and is part of his dissertation in science communication at the Faculty of Humanities at the University of Oulu. The paper shows how opinion mining can be used effectively, and was one of a series presented at the ICI Conference in Bad Nauheim this year. Many of the earlier papers in JISIB came directly from academic or practitioners' conferences. In Vol 2, No 1 (2012) it said: "The journal works in symbioses with a number of conferences. It relies heavily on the contributions of scientific papers presented at these conferences, in particular for these first issues. Among these we would in particular like to mention the more scholarly conferences, like VSST, ECIS, ICTICTI and SIIE. In the near future we also hope to receive contributions 
from INOSA and ECKM. We also receive support from members in the more professional conferences related to Intelligence Studies like ICI and SCIP" (p. 4). And Vol 3, No 3 (2013): "The journal continues to draw mainly on articles presented at academic conferences on topics related to competitive intelligence. In 2013 SCIP organized a first conference in South Africa, under the leadership of ASA du Toit, the journal's editor for Africa.". And in Vol 2, No 3 (2012): "Most contributions continue to come from the best papers from a number of conferences related to Intelligence Studies. Two out of five articles come from ECKM 2012, which was held 6-7 September in Cartagena, Spain.” And in Vol 2, No 2 (2012) echoed a similar sentiment. Today the number of conferences has been reduced for different reasons, which it takes too long to get into here and now.

The last group of articles worth mentioning is opinion pieces. These are non-empirical articles. Today they are less frequent, but at the beginning they served another role, as pointed out in Vol 4, No 1 (2014): "In this issue of JISIB we have admitted a large number of opinion pieces. Opinion pieces are important to allow for a broader perspective of the field in terms of policies, adaptions of $\mathrm{CI}$ in foreign countries and general interest in the form of debates. It also shows the normative qualities that are present in any social science discipline". At the very beginning it was also made clear that the goal was always to be relevant for practitioners. Thus in Vol 1, No 1 (2011) we read: "The final aim of the journal is to be of use to practitioners. We are not interested in theory for the sake of theory, and we do not want to publish solutions to small problems which will have no real impact in the intelligence field.". With your help we try to keep with that goal.

As always, we would above all like to thank the authors for their contributions to this issue of JISIB. Thanks to Dr. Allison Perrigo for reviewing English grammar and helping with layout design for all articles and to the Swedish Research Council for continuous financial support. A special congratulation goes to Rainer Michaeli for having taken the ICI conference to its $10^{\text {th }}$ anniversary. Well done, and thank you for the ongoing cooperation.

On behalf of the Editorial Board,

Sincerely Yours,

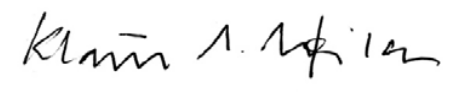

Prof. Dr. Klaus Solberg Søilen Halmstad University, Sweden Editor-in-chief 